\title{
Datura Stramonium Zehirlenmesi Sonucu Antikolinerjik Sendrom: İki Olgu Sunumu
}

Datura Stramonium Intoxication Resulting Anticholinergic Syndrome: Two Case Reports

\author{
Ayşin NALBANTOĞLU ${ }^{1}$, Mustafa Törehan ASLAN ${ }^{1}$, Nedim SAMANCI ${ }^{2}$ \\ Dilek Yaman TAŞ ${ }^{1}$
}

1. Namık Kemal Üniversitesi, Tıp Fakültesi, Çocuk Sağlı̆̆ı ve Hastalıkları Anabilim Dalı, Tekirdă̆

2. Namık Kemal Üniversitesi, Tıp Fakültesi, Çocuk Sağlığı ve Hastalıkları AD, Çocuk Yoğun Bakım Bilim Dalı, Tekirdă̆

\section{$\ddot{O Z Z E T}$}

Boru çiçeği veya melek trompeti adıyla da bilinen Datura stramonium, çok sayıda alkaloid içeren belladonna ailesine ait toksik bir bitkidir. Datura stramonium bitkisinin tüm bölümleri, deliriantlar veya antikolinerjikler olarak siniflandırılan atropin, hiyasiyomin ve skopolamin gibi tehlikeli seviyelerde tropan alkaloidleri içerir. Yüksek miktarda datura stramonium alıminin zehirlenmeye neden olabileceği, genelde delirium (halüsinasyona karşit olarak), hipertermi, taşikardi, tuhaf davranış ve ciddi midriyazisle sonuçlanarak birkaç gün sürecek ăgrılı fotofobi ortaya çıkabilir. Semptomlarin başlanglcı genellikle, bitkiyi aldıktan yaklaşık 30 ila 60 dakika sonra gerçekleşir. Bu semptomlar genellikle 24 ila 48 saat arasinda sonlanır, ancak bazı vakalarda iki haftaya kadar sürdüğ̈̈ bildirilmiştir. Bu yazıda, ă̆ız kuruluğu, öforik semptomlar, görsel halusinasyonlar ve oryantasyon bozukluğu ile acil servise getirilen 6 ve 8 yaşlarındaki kardeşlerin datura stramonium ile zehirlenmesini bildirmekteyiz.

Anahtar Kelimeler: antikolinerjik toksisite; datura stramonium; zehirlenme; deliryum; halüsinasyon

\section{SUMMARY}

Datura stramonium, also known as pipe flower or angel's trumpet, is a toxic plant member of the belladonna family containing several alkaloids. All parts of Datura plants contain tropane alkaloids at dangerous levels, such as atropine, hyaline and scopolamine, classified as deliriums or anticholinergics. High amounts of datura stramonium ingestion may result in painful photophobia, which can lead to poisoning, usually lasting several days, resulting in delirium (as opposed to hallucinations), hyperthermia, tachycardia, strange behavior and severe mydriasis. The onset of symptoms is usually about 30 to 60 minutes after taking the plant. These symptoms usually end between 24 and 48 hours, but have been reported to last up to two weeks in some cases. In this article, we report the poisoning of 6 to 8 year old siblings with datura stramonium, who were brought to the emergency service with dry mouth, euphoric symptoms, visual hallucinations and disorientation.

Keywords: anticholinergic toxicity; datura stramonium; poisoning; delirium; hallucination 


\section{GíRIŞ}

Datura stramonium, Solanaceae familyasının bir üyesi olan, halüsinojenik bir bitkidir $(1,2)$. Bitki ülkemizde geniş çapta dağılmış olmasına ve kolayca erişilebilmesine rağmen, bu bitki ile zehirlenme özellikle çocuklarda çok nadirdir $(3,4)$. Yuttuktan sonra antikolinerjik sendromu indükleyebilen üç alkoloid; atropin, hyosiyamin ve skopolamin içerir. Yüksek miktarda datura stramonium alımında atropinin klinik semptomları olan midriyazis, taşikardi, kuru cilt, flushing, üriner retansiyon, huzursuzluk, ajitasyon, halüsinasyon ve nöbetler görülür(3,4). Çok yüksek dozlarda alımı koma ve ölümle sonuçlanabilir $(5,6)$. Burada datura stramonium zehirlenmesinin klinik özelliklerini, tedavisini ve sonuçlarını tanımlamak için iki vaka sunulmuştur.

\section{OLGU}

6 ve 8 yaşlarında iki erkek kardeş, görsel halüsinasyonlar, oryantasyon bozukluğu, değişmiş zihinsel durum, öforik semptomlar, anormal / tutarsız konuşma ve ajitasyon ile çocuk acil servise getirildi. Birkaç saat önce çocukların sağlıklı olduğu ifade edildi. Nörolojik yada psikiyatrik hastalıklar, enfeksiyon ya da travma öyküsü yoktu ve ilaç almıyorlardı. Şikâyetleri acil servise başvurudan üç saat önce başlamıştı. Anamnezde çocukların yanlışlıkla datura stramonium yaprakları ve tohumlarını yutmuş olduğu öğrenildi, bitki ve bitkinin tohumları ebeveynleri tarafindan kanıt olarak tarafimıza getirildi (Resim 1).

İlk çocuk; 8 yaşında, $25 \mathrm{~kg}$ ve $1.28 \mathrm{~m}$ boyunda olup acil servise başvurduğunda fazlasıyla ajiteydi. Disorientasyon, halüsinojenik deliryum tablosu mevcut olup hakaret içerikli kelimelerle konuşmaktaydı. Glasgow Koma Skalasi 12/15 $(E=4, M=5, V=3)$ idi. İlk fizik muayenede kan basinc1 110/75 mmHg, kalp hızı 112 b.p.m, solunum sayıs1 28 / dakika, oksijen saturasyonu oda havasında \% 98, vücut 1 sis1 $37.9^{\circ} \mathrm{C}$ olup ağız mukozası kuruydu. Nörolojik muayenesinde 1șı̆̆a karșı duyarlı olmayan bilateral midriyazis gözlendi. Derin tendon refleksleri, duyu ve motor muayeneleri normaldi. Laboratuar incelemelerinde; tam kan sayımı ve biyokimyasal parametreler normal sinırlardaydı. İntravenöz kristalloidler ve $4 \mathrm{~L} /$ $\mathrm{dk}$ oksijen desteğinde bulunuldu.Nazogastrik tüp ile aktif kömür (15 g) verildi. Hasta çocuk yoğun bakım ünitesine devredildi. Takiplerinde hemodinamik parametreler stabilseyretti. Ertesi gün huzursuzluğun ve deliryumun azalmasiyla bilinç durumunda iyileşme izlendi. İki taraf11 midriyazis 72 saatte taburcu oluncaya kadar sürdü.

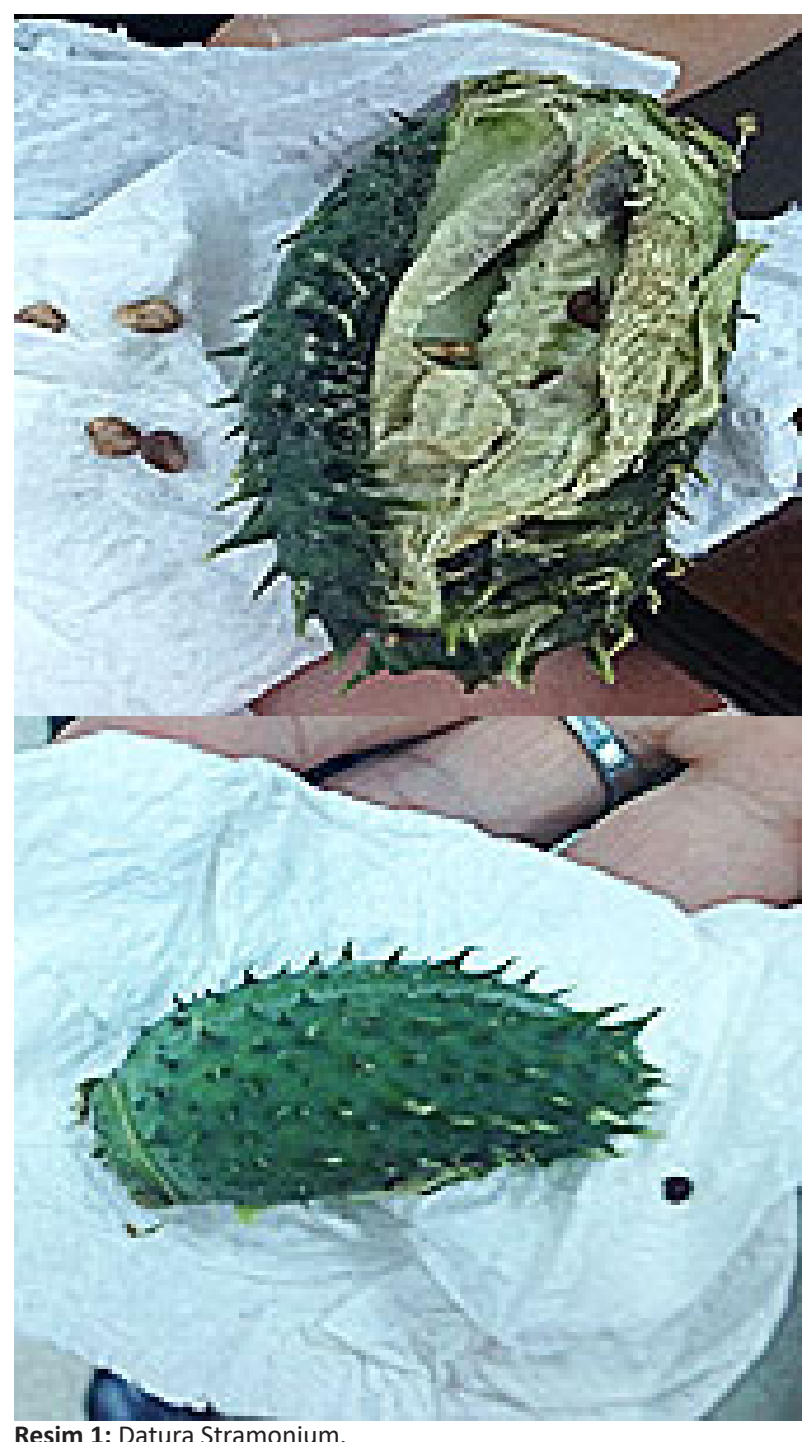

İkinci çocuk 6 yaşında, $20 \mathrm{~kg}, 1,18 \mathrm{~m}$ boyunda olup minimal ajite izlendi. Hastaneye varışında uygunsuz içerikli konuşmaları mevcuttu. Glasgow Koma Skoru başlangıçta 13/15 $(\mathrm{E}=4, \mathrm{M}=5, \mathrm{~V}=4)$ idi. Kan basinc1 $110 / 78$ $\mathrm{mmHg}$ ve nabız 105 atım/dakika, solunum hızı 32 soluk/dakika, oksijen saturasyonu oda havasinda \% 98 ve vücut 1 sisı koltuk alt $37.6^{\circ} \mathrm{C}$ idi. Nörolojik muayene, ışığa karşı zayıf yanıt gösteren bilateral midriyazis (çocuğun pupillaları 6 $\mathrm{mm}$ idi) izlendi.

Kas tonusu ve derin tendon refleksleri normaldi. Fokal nörolojik defisit ve meningeal iritasyon bulguları izlenmedi. Laboratuar incelemelerinde; tam kan sayımı ve biyokimyasal parametreler normal sinırlardaydi. Elektrokardiyografide düzenli sinüs ritmi gözlendi. İntravenöz kristalloidler ve $4 \mathrm{~L} / \mathrm{dk}$ oksijen verildi. Nazogastrik tüp yardımıyla aktif kömür (15 g) uyguland 1 . Hemodinamik parametreler stabil seyretti. 48 saat sonrasinda hasta taburcu edilene kadar midriyazis devam etti. Bilgilendirilmiş onam, çocukların yasal ebeveynlerinden alınd1. 
İlk çocuk; 8 yaşında, $25 \mathrm{~kg}$ ve $1.28 \mathrm{~m}$ boyunda olup acil servise başvurduğunda fazlasiyla ajiteydi. Disorientasyon, halüsinojenik deliryum tablosu mevcut olup hakaret içerikli kelimelerle konuşmaktaydı. Glasgow Koma Skalasi 12/15 $(E=4, M=5, V=3)$ idi. İlk fizik muayenede kan basinc1 110/75 mmHg, kalp h1z1 112 b.p.m, solunum say1s1 28 / dakika, oksijen saturasyonu oda havasinda \% 98, vücut 1 sis $37.9^{\circ} \mathrm{C}$ olup ağız mukozası kuruydu. Nörolojik muayenesinde 1şığa karşı duyarlı olmayan bilateral midriyazis gözlendi. Derin tendon refleksleri, duyu ve motor muayeneleri normaldi. Laboratuar incelemelerinde; tam kan sayımı ve biyokimyasal parametreler normal sinırlardayd1. İntravenöz kristalloidler ve 4 L/ $\mathrm{dk}$ oksijen desteğinde bulunuldu.Nazogastrik tüp ile aktif kömür (15 g) verildi. Hasta çocuk yoğun bakım ünitesine devredildi. Takiplerinde hemodinamik parametreler stabilseyretti. Ertesi gün huzursuzluğun ve deliryumun azalmasiyla bilinç durumunda iyileșme izlendi. İki taraf11 midriyazis 72 saatte taburcu oluncaya kadar sürdü.

İkinci çocuk 6 yaşında, $20 \mathrm{~kg}, 1,18 \mathrm{~m}$ boyunda olup minimal ajite izlendi. Hastaneye varışında uygunsuz içerikli konuşmaları mevcuttu. Glasgow Koma Skoru başlangıçta 13/15 $(\mathrm{E}=4, \mathrm{M}=5, \mathrm{~V}=4)$ idi. Kan basinc1 110/78 $\mathrm{mmHg}$ ve nabız $105 \mathrm{atım} /$ dakika, solunum hız1 32 soluk/dakika, oksijen saturasyonu oda havasinda \% 98 ve vücut 1sisı koltuk altı $37.6{ }^{\circ} \mathrm{C}$ idi. Nörolojik muayene, 1şığa karşı zayıf yanıt gösteren bilateral midriyazis (çocuğun pupillalar1 $6 \mathrm{~mm}$ idi) izlendi. Kas tonusu ve derin tendon refleksleri normaldi. Fokal nörolojik defisit ve meningeal iritasyon bulguları izlenmedi. Laboratuar incelemelerinde; tam kan sayımı ve biyokimyasal parametreler normal sinirlardaydı. Elektrokardiyografide düzenli sinüs ritmi gözlendi. İntravenöz kristalloidler ve 4 L/ dk oksijen verildi. Nazogastrik tüp yardımıyla aktif kömür (15 g) uygulandı. Hemodinamik parametreler stabil seyretti. 48 saat sonrasinda hasta taburcu edilene kadar midriyazis devam etti. Bilgilendirilmiş onam, çocukların yasal ebeveynlerinden alındi.

\section{TARTIŞMA}

"Melek trompeti" veya "Boru çiçeği" olarak da adlandirılan Datura stramonium, atropin benzeri bir etkiye neden olabilecek alkaloidlerin (atropin, skopolamin, hyosiyamin) zenginliği nedeniyle oldukça toksik bir bitkidir $(1,2)$. $\mathrm{Bu}$ alkaloidler çoğunlukla tohum ve yaprakta depolanmakla birlikte, bitkinin diğer bölümlerinde de bulunabilirler. $\mathrm{Bu}$ bitkinin tohumlar1 ve yaprakları daha yüksek toksik kimyasal kon- santrasyonları içerir, bu nedenle bitkinin diğer kısımlarına göre daha zehirlidir. Türkiye'de yaygın olarak bulunan bir bitkidir, ancak çocuklarda Datura stramonium zehirlenmesi, genellikle kaza ile olup , çok nadirdir $(3,4)$.

Tüm Datura bitkilerinde bulunan baskın kimyasal maddeler olan Tropane alkaloidleri, antikolinerjik etkili ve merkezi sinir sistemi uyarıcılarıdır. Muskarinik reseptörlerde asetil kolini yarışmalı ve geri dönüşümsüz olarak inhibe ederek etkilerler ve böylece hem merkezi hem de periferik sinir sistemine etkili olurlar. Antikolinerjik aktivite belirtileri ve semptomları yutulduktan 1-4 saat sonra ortaya çıkar ve alkaloidler gastrointestinal motilite'yi geciktirdiği için 24-48 saat devam edebilir (7). Olgularımızda, belirtiler ve semptomların başlangıcı ve ilerleme süreleri ve farklılıkları literatür ile benzerdi.

Çocuklar özellikle bu zehirlenme konusunda duyarlıdırlar. Hastalarımızdan birinde arasında huzursuzluk, deliryum, değişen duyusal bulgular ve halüsinasyonların izlendiği merkezi sinir sistemi bulguları izlendi. Ayrıca şiddetli intoksikasyonda konvülsiyonlar ve derin komaya da rastlanabilmektedir (8). Periferik sinir sistemi bulguları, hiperpireksi, pupil dilatasyonu, ağız mukozası ve cilt kuruluğu, üriner retansiyon ve gastrik motilitenin azalmasinı içerir. Dahası, merkezi sinir sistemi depresyonuna bağlı ölüm, dolaşımda kollaps ve hipotansiyon olabilir $(5,6)$. Bu özelliklerin çoğu bizim hastalarımızda da görüldü. Biyolojik değerlendirmeler genellikle normaldir ve spesifik teşhis biyolojik bulgularla açıklanamaz. Ayırıcı tanı için toksikolojik araştırmalar gerekebilir (6).

Datura stramonium, alternatif tıpta, astım, kronik bronşit, grip belirtileri ve ağrı gibi sık görülen hastalıkları tedavi etmek için kullanılmaktadır. Bu sunumdaki iki çocukta bitkinin kaza ile yutulması sonrasında toksisite gelişmişti. Tropane alkaloidlerinin yanlışlıkla yutulması sonucu zehirlenme daha önce literatürde bildirilmiş ve ölümle sonuçlanan vakalara rastlanmıştır $(9,11)$. Birleşik Devletler'den bildirilen birkaç vakada alkaloid zehirlenmesi, evde kullanılan diş macunu içine Datura stramonium ektresinin eklenmesi ve yenilebilir bir sebze olarak bitkinin yanlış kullanılması sonrasında saptanmıştı $(10,11)$. Bazı Avrupa ülkelerinde, ticari olarak satın alınan bal, Paraguay çayı, hamburger ve sebze püreleri gibi gida kontaminasyonu sonrasinda zehirlenmeler izlendi. Tedavide konservatif, destekleyici bakım [ABC, kardiyak izleme, i.v.hidrasyon, gastrointestinal dekompresyon (örn. Mide yıkaması, kusma ve / veya aktif kömür)] ve ağır vakalarda 
fizostigmin uyguland1 (12). Biz de sunduğumuz her iki olguda aynı tedavi protokollerini fizostigmin olmadan uyguladık. Gastrik lavaj ve aktif kömür uygulaması önemlidir ve antikolinerjik ajanlar midede uzun süre kalabileceğinden alımından sonraki 12 ile 24 saatte önerilir. Birçok çalışmada, datura stramonium zehirlenmesi olan hastaların çoğunluğu sadece genel destek tedavisine ve semptomatik tedaviye ihtiyaç duymuştur $(12,13)$. Hastalarımız verilen ilk konservatif tedaviye iyi yanıt verdiklerinden, hiçbirinde fizostigmin veya takrin hidroklorür tedavisine ihtiyaç duyulmamıștır.

Sonuç olarak, bitki zehirlenmelerinin erken teşhisi ve tedavisi, yüksek potansiyel ölümcül olmaları nedeniyle çok önemlidir ve bu nedenle doktorlar ağız kuruluğu, çarpıntı, görme bozukluğu, işitsel halüsinasyonlar ve deliryum semptomları ile başvuran hastalarda antikolinerjik toksisiteye karşı dikkatli olmalıdırlar ve hemen antitoksik tedaviye başlamalıdırlar. Bu nadir vaka sunumları, toksisitelerin ve farklı türde bitkiler için potansiyel risklerin önemini vurgulamakta, ayrıca çocukların ve ergenlerin, ebeveynlerinin istismarına veya bunları yanlışlıkla kullanmaya karşı korunması ve eğitilmesinin önemini de hatırlatmaktadır.

\section{KAYNAKLAR}

1. Montcriol A, Kenane N, Delort G, Asengio Y, Palmier $B$. Intentional datura stramonium intoxication: an unknown etiology of mydriasis. Ann. Fr. Anesth Reanim. 2007;26: 810-813.

2. Bouziri A, Hamdi A, Borgi A, et al. Datura stramonium L. poisoning in a geophagus child: a case report. Int. J. Emerg. Med.2011;4 (1): 31.
3. Özkaya AK, Güler E, Karabel N, Namlı AR, Göksügür $Y$. Datura stramonium poisoning in a child. Turk J Pediatr. 2015;57: 82-84.

4. Şanlıdăg B, Derinöz O, Yıldız N. A case of pediatric age anticholinergic intoxication due to accidental datura stramonium ingestion admitting with visual hallucination. Turk J Pediatr. 2014;56(3): 313-315.

5. Urich RW, Bowerman DL, Levisky JA, Pflug JL. Datura stramonium: a fatal poisoning. J Forensic Sci. 1982;27(4): 948-954.

6. Boumba VA, Mitselou A, Vougiouklakis T. Fatal poisoning from ingestion of Datura stramonium seeds. Vet Hum Toxicol. 2004;46(2): 81-82.

7. Vanderhoff BT, Mosser KH. Jimson weed toxicity: management of anticholinergic plant ingestion. Am Fam Physician. 1992;46(2): 526-530.

8. Diker D, Markovitz D, Rothman M, Sendovski U. Coma as a presenting sign of Datura stramonium seed tea poisoning. Eur J Intern Med. 2007; 18: 336-338.

9. Ramirez M, Rivera E, Ereu C. Fifteen cases of atropine poisoning after honey ingestion. Vet Hum Toxicol 1999;41: 19-20.

10. Chang SS, Wu ML, Deng JF, Lee CC, Chin TF, Liao SJ. Poisoning by Datura leaves used as edible wild vegetable. Vet Hum Toxicol 1999;41: 242-245.

11. Pereira CA, Nishioka Sde D. Poisoning by the use of Datura leaves in a homemade toothpaste. J Toxicol Clin Toxicol 1994;32: 329-331.

12. Francis PD, Clarke CF. Angel trumpet lily poisoning in five adolescents: clinical findings and management. $J$ Paediatr Child Health. 1999;35(1): 93-95.

13. Rakotomavo F, Andriamasy C, Rasamoelina N, Raveloson N. Datura stramonium intoxication in two children. Pediatr Int. 2014;56(3): 14-16. 